\title{
Improving Impact Toughness for Welding Joints of Steel by Adding $\mathrm{TiO}_{2}$ Nanoparticales
}

\author{
Ali Fakhri Al-Obaid ${ }^{1 *}$, Ali Sadiq Yasir ${ }^{2}$, Sabah Mresn Thahab ${ }^{3}$ \\ ${ }^{1}$ Southern Cement State Company, Kufa Cement Plant, Najaf, Iraq; ${ }^{2}$ Mechanical Engineering Department, Faculty of Engineering, \\ University of Kufa, Najaf, Iraq; ${ }^{3}$ Nanotechnology and Advanced Materials Research Unit (NAMRU), Faculty of Engineering, University \\ of Kufa, Najaf, Iraq
}

\begin{abstract}
The using of nanotechnology in the welding process has great importance in developing the mechanical properties of welding joints for metals. This paper investigated the effect of addition $\mathrm{TiO}_{2} \mathrm{NPs}$ to welding joints to improving the Impact toughness property of the welding joints. The cold spray coating method of the nanoparticles are used to adding the $\mathrm{TiO}_{2} \mathrm{NPs}$ to the welding joints during the welding process. Three weight fraction are used for $\mathrm{TiO}_{2} \mathrm{NPs}$ $(0.75 \%, 1.5 \%$, and $2 \%)$. The testing samples were prepared for Impact test, and microstructure by SEM. The results show the increasing in Impact toughness of welded joints with an increase of $\mathrm{TiO}_{2} \mathrm{NPs}$ concentrations. The average Impact toughness for the welded sample without $\mathrm{TiO}_{2} \mathrm{NPs}$. was (162.4 J), while the average Impact toughness for the welded sample with (1.5)\% $\mathrm{TiO}_{2} \mathrm{NPs}$. was (231.2 J) with improving rate of (42.36\%). The Microstructure images by SEM show the adding of $\mathrm{TiO}_{2}$ NPs decreases the grain size and homogenous region in welded joints cross-section compared with a sample without adding $\mathrm{TiO}_{2}$ NPs. The EDS analysis show that increase Ti contain and decrease ( $\mathrm{Mn}$ and $\mathrm{Si}$ ) contain with increase $\mathrm{TiO}_{2} \mathrm{NPs}$.
\end{abstract}

Keywords: Steel welding; $\mathrm{TiO}_{2}$ nanoparticles; Nano welding; Impact toughness

\section{INTRODUCTION}

Titanium dioxide $\left(\mathrm{TiO}_{2}\right) \mathrm{NPs}$ were used to create a new types of metal matrix composite materials (MMCM) in many engineering applications. $\mathrm{TiO}_{2} \mathrm{NPs}$ have many suitable properties because of chemically stability, exhibits an efficient photocatalytic effect and nontoxic effects [1,2]. The disadvantages of traditional epoxy additives such as glass and rubber beads can be control of the application of $\mathrm{TiO}_{2}$ rising the strength, stiffness, and toughness without reducing its thermo-mechanical properties [3]. Also, the other types of $\mathrm{TiO}_{2}$, as well as $\mathrm{TiO}$ and $\mathrm{Ti}_{2} \mathrm{O}_{3}$, show the mechanisms of rising nucleation rate and ferrite grain delayed growth lead to effectual in rising the number of nucleation locations for intragranular acicular ferrite in welding zones [4-9]. During welding process, the decrease of $\mathrm{TiO}_{2}$ lead to the existence of titanium in the weld zone that may produce $\mathrm{TiC}, \mathrm{TiN}$ and $\mathrm{Ti}_{2} \mathrm{O}_{3}$ results. In the weld zones, there are four kinds of ferrite can be appearing: intragranular acicular, grain boundary allotriomorphic, Widmanstätten, and intragranular idiomorphic. The intragranular acicular ferrite phase increase with increasing the $\mathrm{TiO}_{2} \mathrm{NPs}$. Its fine microstructure, nucleates intragranular in the shape of separate strips on non-metallic implying inside austenite grains [10]. The best combination of mechanical properties due to increase in density of high angle grain boundaries.

The different of crystallographic orientation in Grain boundaries lead to change crack growing direction by stand-in as strong barriers [10-13]. Fattahi et al. studied improving the mechanical properties of welding zone by the addition of $\mathrm{TiO}_{2} \mathrm{NPs}$ to the electrode coating and investigated the effect of nucleation of intragranular ferrite. It was presented that the quantity of Titanium in the weld zone rising an acicular ferrite, while the $\mathrm{Mn}$ and $\mathrm{Si}$ quantities were reduced.

Also, the rise in the amount of Mn-Ti complex oxide inclusions in the welding zones lead to variation in the microstructure of columnar zones from Widmanstätten ferrite and allotriomorphic ferrite to fine intragranular ferrite. The other influence was improved the tensile strength and impact toughness properties of the welding zones due to the ultrafine grain size of the ferrite for the reheated zones [14]. Pal et al. used wire electrode consists

Correspondence to: Ali Fakhri Al-Obaid, Southern Cement State Company, Kufa Cement Plant, Najaf, Iraq, Tel: +964 780 056 6527 ; E-mail: alif. alobaidi@student.uokufa.edu.iq

Received: November 26, 2019, Accepted: January 25, 2020, Published: February 03, 2020

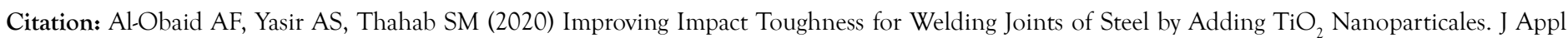
Mech Eng. 9:323. doi: 10.35248/2168-9873.20.9.323

Copyright: ( $) 2020$ Al-Obaid AF, et al. This is an open access article distributed under the term of the Creative Commons Attribution License, which permits unrestricted use, distribution, and reproduction in any medium, provided the original author and source are credited. 
of $(1.5 \%) \mathrm{TiO}_{2}$ micro particles, but $(33.333) \%$ of the $\mathrm{TiO}_{2}$ micro particles was replaced by $\mathrm{TiO}_{2}$ NPs. Four sample were tested, two samples without $\mathrm{TiO}_{2} \mathrm{NPs}$ and two samples with $\mathrm{TiO}_{2} \mathrm{NPs}$ through welding They obtained an improvement rate in tensile strength and Charpy impact [15]

The electrode coating by $\mathrm{TiO}_{2}$ NPs achieved improving in mechanical properties of the weld zones $[14,15]$. In this paper, the effect of $\mathrm{TiO}_{2}$ NPs on the Impact toufghness, the nucleation of intragranular ferrite, and microstructure of weld metals will be carried out in investigated using the cold spray coating method to add nanoparticles on welding joints. The Impact toughness and Microstructure of welded joints will be tested using addition $\mathrm{TiO}_{2}$ NPs through the thickness of welded joints of St-37 low carbon steel by using standard specification.

\section{EXPEREMENTAL WORK}

Three weight percentage (Wt\%) of $\mathrm{TiO}_{2}$ NPs colloidal $(0.75$, 1.5 , and 2$) \%$ was added to weld metal by the cold spray coating method were provided from US Research. Inc., anatase type with an average particle size (10-25) $\mathrm{nm}$. The wire electrode AWS E6013 (4 mm diameter) was used to weld specimens. St-37 base metal was used for this research with dimensions of $(250 \mathrm{~mm} \times 200 \mathrm{~mm} \times 20$ $\mathrm{mm})$. The chemical analysis of wire electrode and base metal are presented in Table 1.

The colloidal of $\mathrm{TiO}_{2}$ NPs was prepared by dissolving of (2.76, 5.53 and $7.37 \mathrm{~g})$ in $(20 \mathrm{ml})$ of distilled water to provide $(0.75$, 1.5 and 2)\% wt. respectively according to equation (1) by using Magnetic Stirrer instrument (Jenway Company, UK), and mixed by Ultrasonic mixing liquid instrument (MTI Corporation company, USA) in the nanotechnology unit at the Faculty of Engineering at the University of Kufa.

$$
\% \mathrm{wt}=\frac{\frac{w_{n}}{\rho_{n}}}{\frac{w_{n}}{\rho_{n}}+\frac{w_{f}}{\rho_{f}}} \times 100
$$

Where:

$w_{n}=$ weight for nanoparticles $(\mathrm{g})$

$\rho_{n}=$ density for nanoparticles $\left(3.9 \mathrm{~g} / \mathrm{cm}^{3}\right.$ for $\mathrm{TiO}_{2}$ (anatase) $)$

$w_{f}=$ weight of welding filler $(\mathrm{g})$

\section{$\rho_{f}=$ density for welding filler $\left(7.64 \mathrm{~g} / \mathrm{cm}^{3}\right)$}

The cold spray coating method was used to add the $\mathrm{TiO}_{2}$ NPs colloidal to each pass of welding process. The welding zone was coated by $\mathrm{TiO}_{2}$ nanoparticle after cleaning of the welding slag after measuring of temperature of the welding zone before coating process. It was found that the best adhesives of $\mathrm{TiO}_{2} \mathrm{NPs}$ obtained at $300^{\circ} \mathrm{C}$ temperature. Followed by another welding layer. It was observed that the temperature of the welding zone before the coating was an important factor. Also at high temperatures greater than $500^{\circ} \mathrm{C}$ gets rapid drying in $\mathrm{TiO}_{2}$ nanoparticle colloidal was occurred leading to a situation of flaking and non-adhesion of $\mathrm{TiO}_{2} \mathrm{NPs}$ on the welding zone. While at low temperatures less than $200^{\circ} \mathrm{C}$, the colloidal was dried slowly so that the colloidal was pushed out of the welding zone, because of the pressure of the air compressor. The temperature measurement was done by the manual infrared thermometer instrument. The St-37 specimens were lathing in mechanical workshop of the Kufa cement plant.

\section{Impact test}

A 20-mm thickness (St-37) low carbon steel was used and cut to $(190 \mathrm{~mm} \times 125 \mathrm{~mm})$, and the preparation of Impact toughness specimen was (25). Five specimens from base metal (B), five of which were welding without the addition of nanoparticles (W), and the remaining fifteen by added of $\mathrm{TiO}_{2} \mathrm{NPs}(0.75,1.5$, and $2) \%,\left(S_{1}, S_{2}\right.$ and $\left.S_{3}\right)$ respectively, five specimens for each ratio. The weld dimensions of the weld pool for the preparation and formation of the Impact toughness specimen were as shown in Figure 1 [16,17]. The specimens were welded by E6013 (4 mm) wire electrode dimeter at 200 A current by AC welding Machin, and then tested the welding by portable ultrasonic flaw detector instrument to detect the defects of welding before testing. Since the plate used for the design and preparation of specimen was 20 $\mathrm{mm}$, the number of passes to fill the entire weld pool was fourteen pass distributed over seven layers (two pass for each layer) [17]. As according to our research procedure, the added nanoparticles were distributed only to the four middle layers because they are the only ones that include the diameter of the tensile specimen type and according to the method of addition nanoparticle mentioned above. Therefore, there was no need to add nanoparticles to the welding layers at the top and bottom of the welding area. After the full weld pool was filled.

The specimen's surfaces were scraped a $5 \mathrm{~mm}$ by milling machine for each surface of the specimen. Final thickness of the specimens was $10 \mathrm{~mm}$. The specimens were then being cut to $55 \mathrm{~mm}$ long and $10 \mathrm{~mm}$ width by an automatic horizontal band saw as shown in the Figure 1 with coolant solution [16,17]. The milling machine was used to preparation the weld specimen as shown in Figure 2. The impact testing was performed on a V-notched specimen with $(500 \mathrm{~J})$ value of kinetic energy. The specimens are fixed horizontally and hit with a heavy pendulum. The pendulum speed is about 4.8 $\mathrm{m} / \mathrm{s}$. Note that all operations were carried out at the mechanical workshop at Kufa Cement Plant. The type of instrument was used (HECKRT, Company, Germany origin) in the Applied Mechanics Laboratory at the Faculty of Engineering at the University of Kufa.

In this test, five specimens were cut by hand saw which taken from round tensile specimens after testing. One of the specimen of

\begin{tabular}{ccccccccccc}
\hline Sample & $\mathrm{C}$ & $\mathrm{Si}$ & $\mathrm{Mn}$ & $\mathrm{P}$ & $\mathrm{S}$ & $\mathrm{Cu}$ & $\mathrm{Cr}$ & $\mathrm{Ni}$ & $\mathrm{Mo}$ & $\mathrm{V}$ \\
\hline Base material & $\leq 0.13$ & $0.1-0.4$ & $0.2-0.5$ & 0.05 & 0.035 & $0.03-0.05$ & $0.05-0.08$ & 0 & 0 & 0 \\
\hline Wire electrode & 0.2 & 1 & 1.2 & N.S & N.S & 0 & 0.2 & 0.3 & 0.3 & 0.08 \\
\hline
\end{tabular}

Table 1: Chemical analysis (Wt \%) of core wire electrode (E6013) and base metal (St-37). 

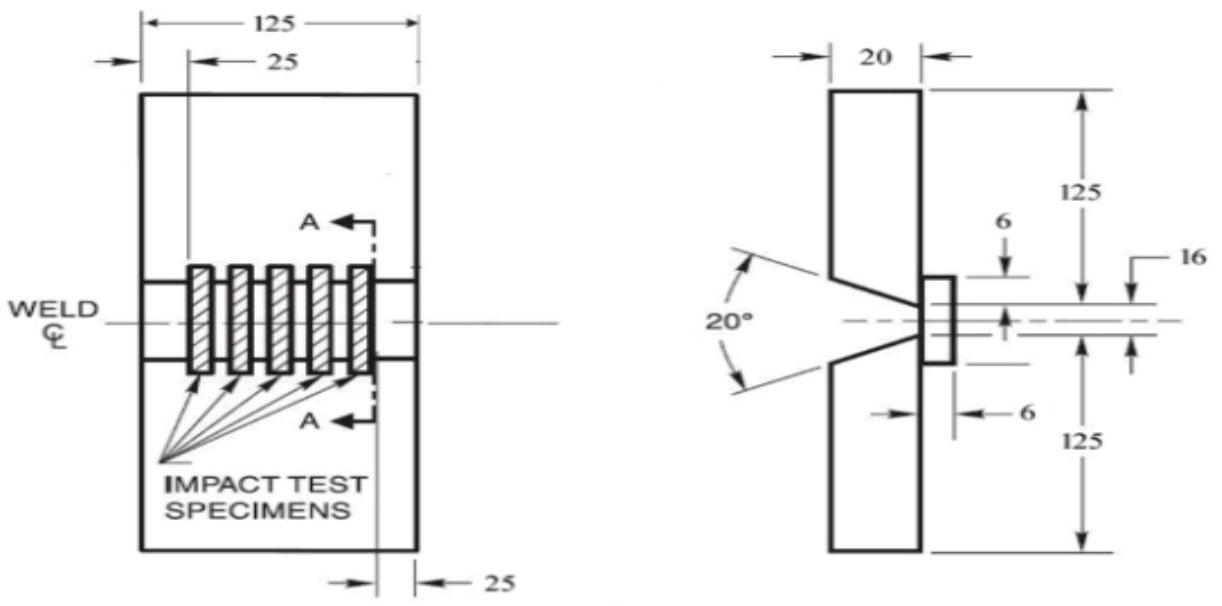

(A) TEST PLATE SHOWING LOCATION OF TEST SPECIMENS

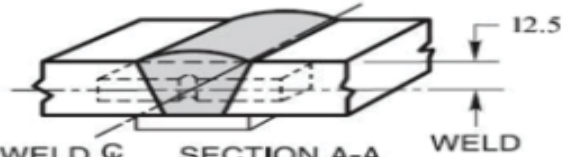

WELDG SECTION A-A WELD

(B) ORIENTATION AND LOCATION OF IMPACT TEST SPECIMEN

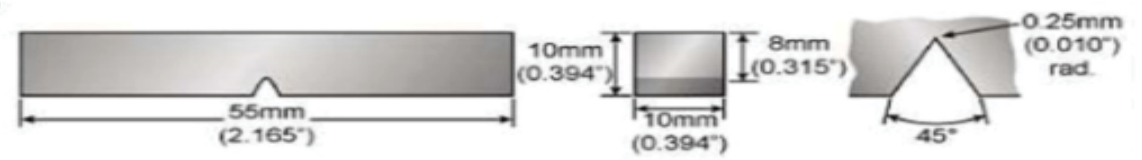

(c) Impacte test specimen dimension

Figure 1: Specimen of impact testing.

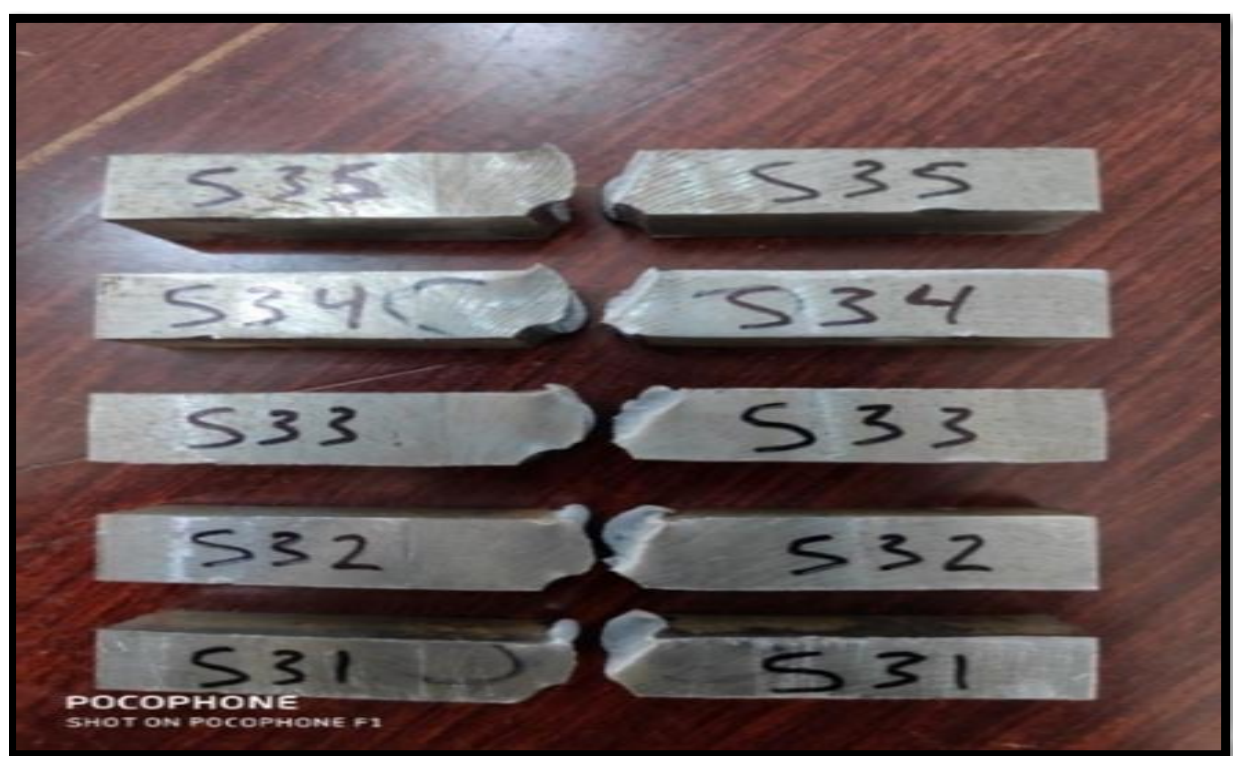

Figure 2: Impact specimens after the test.

the base metal (B) and one of the specimen welding without the addition of nanoparticles (W) and three specimens welding with

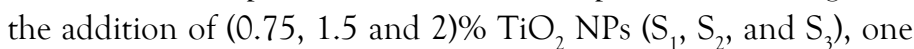
test sample for each added of the specimen surface as shown in Figure 2.

\section{Microstructure image test}

In this test, five specimens were cut by hand saw which taken from round tensile specimens after testing. One of the specimen of the base metal (B) and one of the specimen welding without the addition of nanoparticles (W) and three specimens welding with

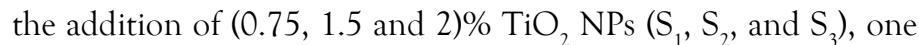
sample for each ratio.

The specimen dimensions were $(\varnothing 13 \times 10 \mathrm{~mm})$. After the cutting process, the specimen surfaces were prepared, grinding and polished by the grinding and polished instrument, and used in the grades of grinding paper $(240,320,400,600,800,1000$ and 1200) respectively. The time of the grinding surface of the 
specimen was five minutes for each paper grinding. Then polishing the surfaces with alumina emulsion materials for a five minutes for each specimen. The surface of the specimen was etched with $2 \%$ Nitric acid (Nital) in water, by immersing the surface of the specimen for one minute in the solution. Following washing the surface with distilled water and drying it with hot dry air. The type of instrument was used the optical microscope instrument (1600X) (MTI Corporation Company, 1600X, USA origin) in the laboratories of the Nanotechnology Unit at the Faculty of Engineering at the University of Kufa with magnification power (10X) was used. Five microscopic tests were taken at the centre of the surface for each specimen and four others at a $(0,90,180,270)$ degree of the specimen surface as shown in Figure 3.

\section{FE-SEM and EDS tests}

The selected specimens for (FE-SEM) test and (EDS) test were the same specimen used in microstructure test as shown in Figure 4. The tests were point and mapping. The type of instrument of FESEM and EDS tests was used (TESCAN, Mira 3, French origin).

\section{RESULTS AND DISCUSSION}

Table 2 shows the results for Charpy impact specimen's test with and without addition of nanoparticles. The average Charpy impact for specimen's test $(\mathrm{W})$ was $(162.4 \mathrm{~J})$, while the best average Charpy impact for specimen's test of the welded area by E6013 with

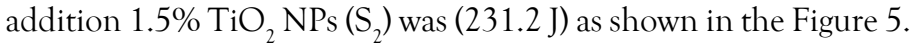
The improvement ratio is $(42.36 \%)$ as shown in the Figure 6 . Note

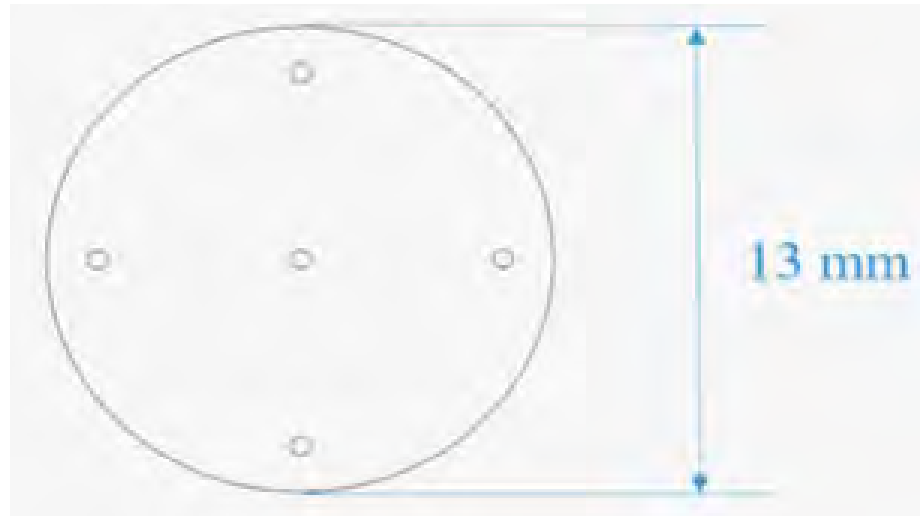

Figure 3: Location of tested points.

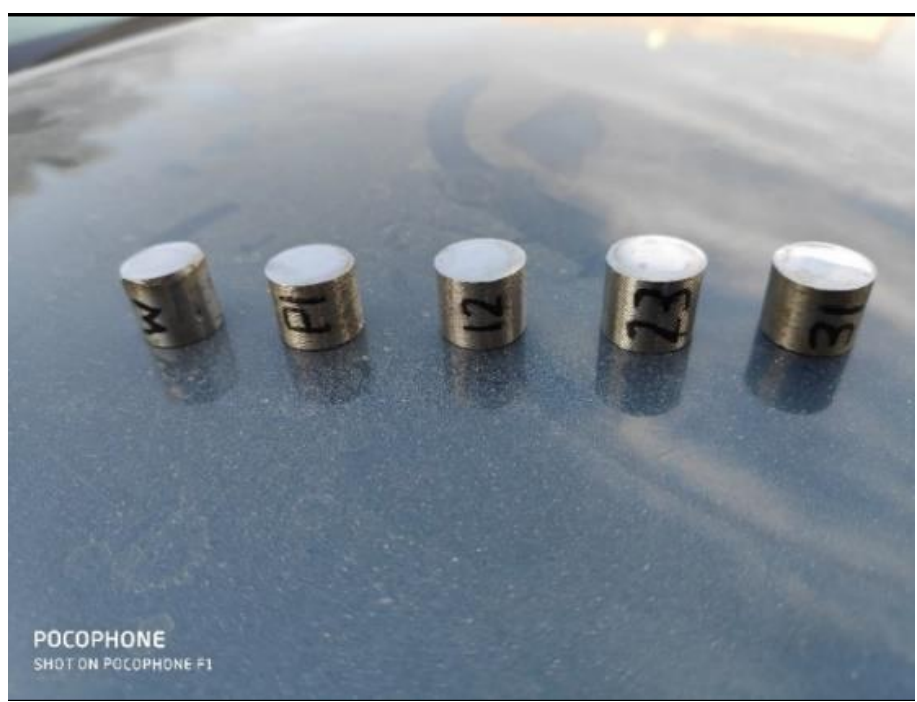

Figure 4: The prepared specimens for SEM and EDS tests.

\begin{tabular}{cccccc}
\hline S3 & S2 & S1 & W & B & Number \\
\hline 156 & 224 & 204 & 172 & 110 & 1 \\
\hline 184 & 210 & 210 & 158 & 108 & 2 \\
\hline 172 & 250 & 216 & 164 & 112 & 3 \\
\hline 196 & 224 & 194 & 162 & 105 & 4 \\
\hline 148 & 248 & 202 & 156 & 110 & 5 \\
\hline 171.2 & 231.2 & 205.2 & 162.4 & 111 & AV. \\
\hline 5.41 & 42.36 & 26.35 & 0 & 0 & Improvement\% \\
\hline
\end{tabular}

Table 2: Results for impact test (J).

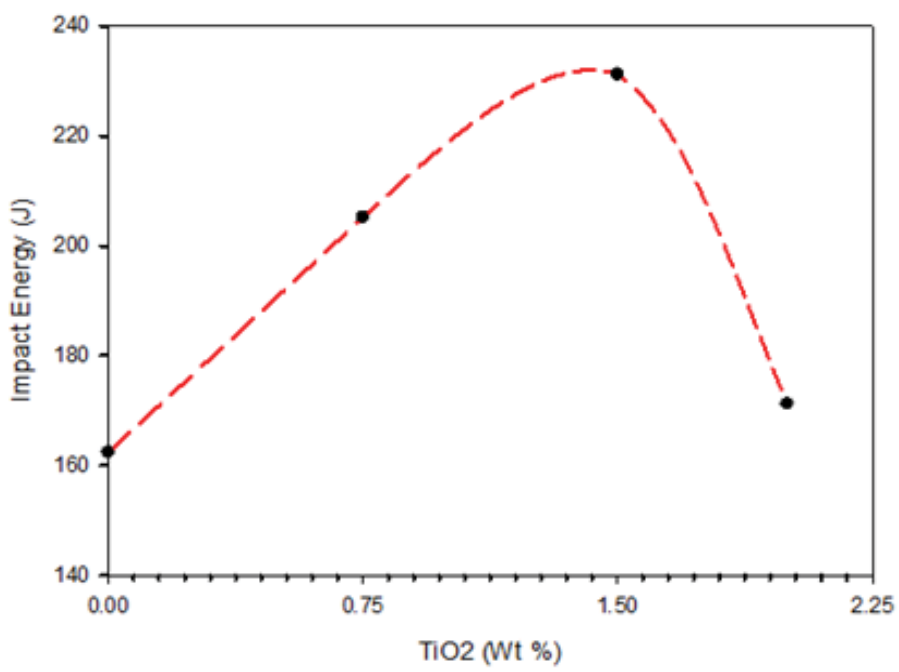

Figure 5: Impact toughness with additives of $\mathrm{TiO}_{2} \mathrm{NPs}$ wt $\%$.

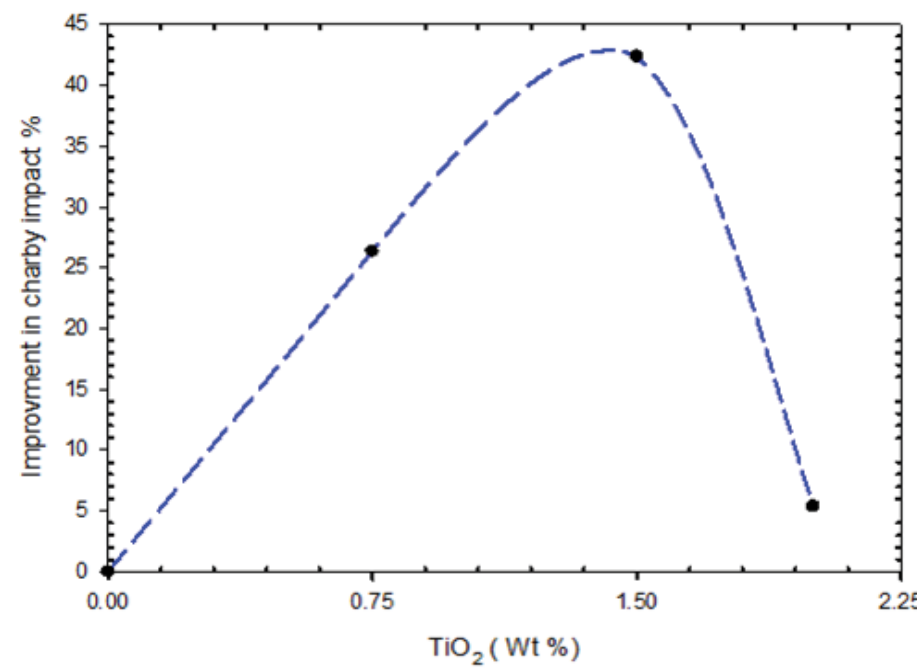

Figure 6: The improvement in impact toughness with additives of $\mathrm{TiO}_{2}$ NPs wt $\%$.

that increasing the ratio of $\mathrm{TiO}_{2}$ nanoparticles in welding joints lead to increasing Impact toughness because of increasing the intragranular acicular ferrite. Intragranular acicular ferrite due to the increased density of high-angle boundaries. Often, boundaries have been indicated to change direction on crack growth by make strong barriers, due to have a various crystallographic orientation $[14,18]$. And note that increasing the ratio of $\mathrm{TiO}_{2}$ nanoparticles in welding joints above $1.5 \%$ resulted a decrease in impact toughness. This is due to the increase in the ratio of oxygen, as with the increase of $\mathrm{TiO}_{2}$ nanoparticles increase the ratio of oxygen, as previous studies have shown that the increase of oxygen harmful effects on the impact toughness $[19,20]$. 
The microstructure of weld specimen (W) as shown in Figure 7a shows high amount of Widmanstätten ferrite and large grain size. The microstructure of weld specimen $\left(\mathrm{S}_{1}\right)$ as shown in Figure $7 \mathrm{~b}$ shows the existence of acicular ferrite, a high quantity of Widmanstätten ferrite, and grain boundary ferrite happen as a result of the low $\mathrm{TiO}_{2} \mathrm{NPs}$ in the welding zone. The microstructure of weld specimen $\left(\mathrm{S}_{2}\right)$ as shown in Figure 7c, contain Widmanstätten ferrite and grain boundary ferrite with an influent grain growth happen as a result of the $\mathrm{TiO}_{2} \mathrm{NPs}$ in the weld area and grain size was medium. The microstructure of weld specimen $\left(\mathrm{S}_{3}\right)$ as shown in Figure $7 \mathrm{~d}$ was composed mainly of small proportion of grain boundary with an acicular ferrite and very small of Widmanstätten ferrite happen as a result of the high $\mathrm{TiO}_{2} \mathrm{NPs}$ in the weld area and have small grain size. The results investigated that the adding of $\mathrm{TiO}_{2} \mathrm{NPs}_{\mathrm{s}}$ increases the slag and thus decreases the cooling rate and reduces the Widmanstätten phase occurred as a result of reduced the cooling rate which is required in $\%$ welding processes, and the adding of $\mathrm{TiO}_{2}$ NPs decrease the grain size [14].

The results of EDS test shows that the amount of $\mathrm{Ti}$ increased with the adding of $\mathrm{TiO}_{2} \mathrm{NPs}$ to the welding zone and the quantity of Oxygen increased with the addition of $\mathrm{TiO}_{2} \mathrm{NPs}$. On the contrary, the amount of $\mathrm{Mn}$ and $\mathrm{Si}$ decreased with the increase of $\mathrm{TiO}_{2} \mathrm{NPs}$. These results could be described by the following reactions $(2,3)[21]$.

$\mathrm{Si}+2 \mathrm{O} \leftrightarrow \mathrm{SiO}_{2}$

$\mathrm{SiO}_{2}+2 \mathrm{Mn} \leftrightarrow 2 \mathrm{MnO}+\mathrm{Si}$
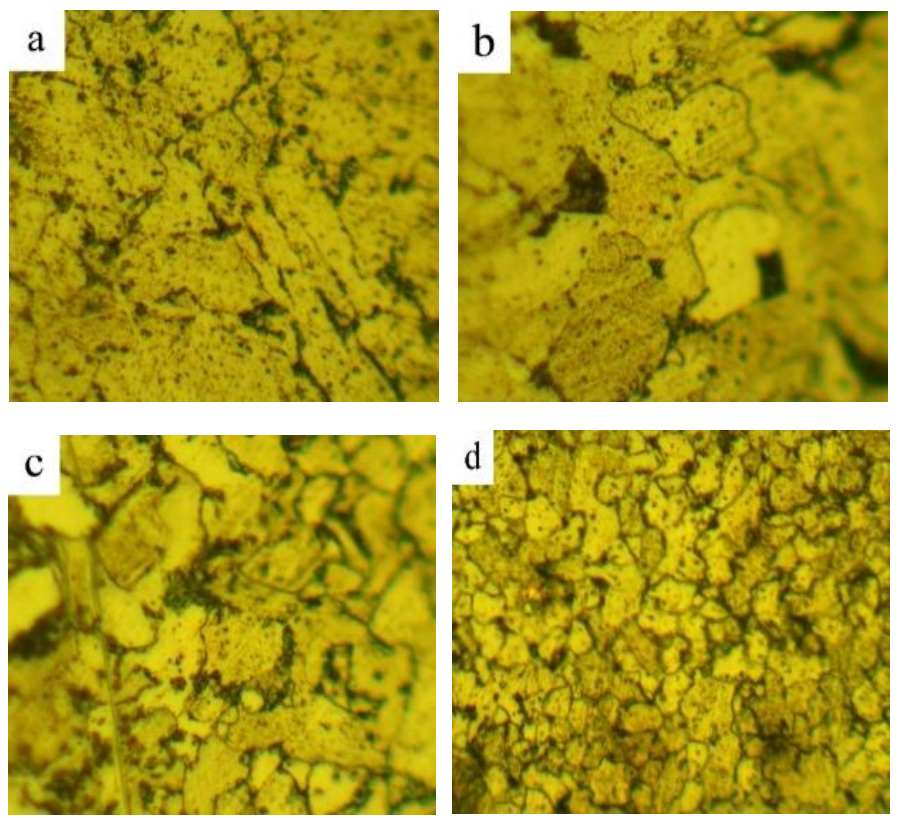

Figure 7: Images for microstructure a) W specimen b) $S_{1}$ specimen c) $S_{2}$ specimen d) $\mathrm{S}_{3}$ specimen.

\begin{tabular}{ccccccc}
\hline Elt & Line & Int & Error & $\mathbf{K}$ & $\mathbf{K r}$ & $\mathrm{Wt}_{\mathbf{t}}$ \\
\hline $\mathrm{C}$ & $\mathrm{Ka}$ & 68.5 & 142.184 & 0.0155 & 0.0138 & 5.24 \\
\hline $\mathrm{O}$ & $\mathrm{Ka}$ & 133.1 & 142.184 & 0.0306 & 0.0272 & 4.84 \\
\hline $\mathrm{Si}$ & $\mathrm{Ka}$ & 103 & 228.8563 & 0.0256 & 0.0227 & 3.51 \\
\hline $\mathrm{Ti}$ & $\mathrm{La}$ & 44 & 144.3423 & 0.0101 & 0.0082 & 1.09 \\
\hline $\mathrm{Mn}$ & $\mathrm{La}$ & 426.5 & 142.184 & 0.0989 & 0.0878 & 9.93 \\
\hline $\mathrm{Fe}$ & $\mathrm{Ka}$ & 2572.9 & 2.9738 & 0.8186 & 0.7273 & 75.39 \\
\hline & & & & 1 & 0.8884 & 100
\end{tabular}

Table 3: Quantitative results for the (W) welding specimen.
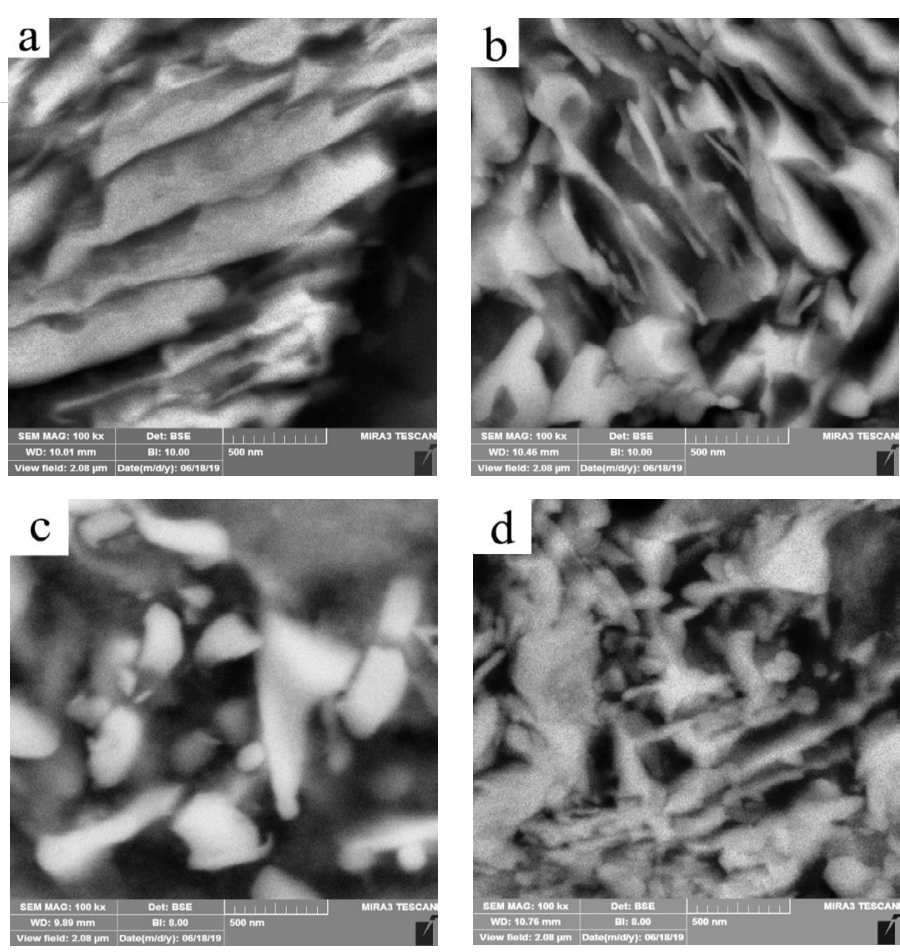

Figure 8: SEM images of weld specimens (a) W (b, c, d) (S1, S2, and S3) specimens respectively.

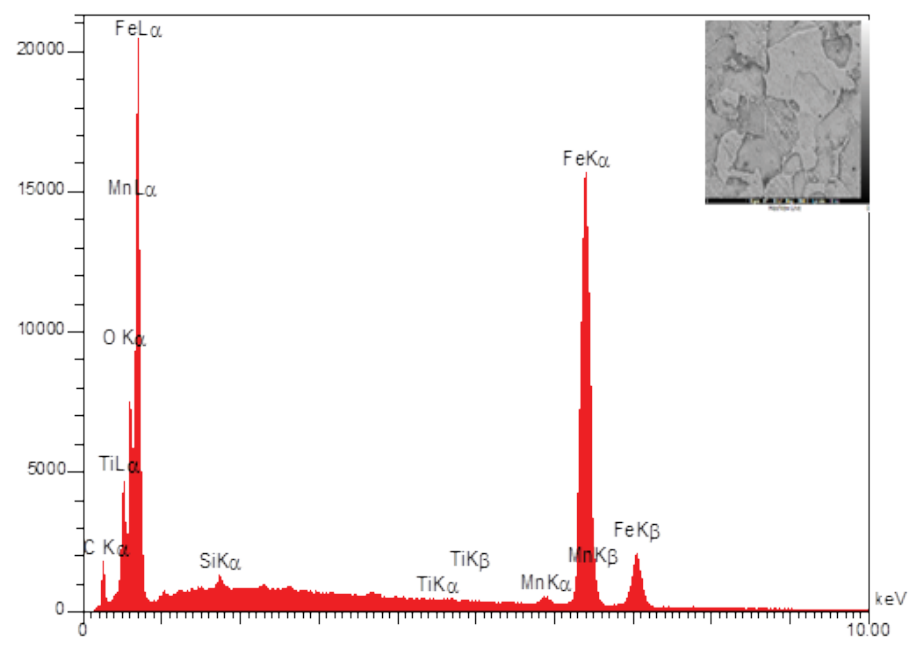

Figure 9: EDS analysis for the (W) welding specimen.

\begin{tabular}{ccccccc}
\hline Elt & Line & Int & Error & K & Kr & Wt \% \\
\hline $\mathrm{C}$ & $\mathrm{Ka}$ & 115.4 & 144.3423 & 0.0263 & 0.0213 & 7.84 \\
\hline $\mathrm{O}$ & $\mathrm{Ka}$ & 343.6 & 144.3423 & 0.0794 & 0.0643 & 11.86 \\
\hline $\mathrm{Si}$ & $\mathrm{Ka}$ & 82.1 & 205.309 & 0.029 & 0.0234 & 3.06 \\
\hline $\mathrm{Ti}$ & $\mathrm{La}$ & 49.6 & 143.8454 & 0.0113 & 0.0096 & 1.27 \\
\hline $\mathrm{Mn}$ & $\mathrm{La}$ & 326.7 & 144.3423 & 0.0761 & 0.0616 & 8.56 \\
\hline $\mathrm{Fe}$ & $\mathrm{Ka}$ & 2437.4 & 2.9474 & 0.7791 & 0.6305 & 67.41 \\
\hline & & & & 1 & 0.8093 & 100
\end{tabular}

Table 4: Quantitative results for the (S3) welding specimen.

Table 3 shows that the values of the Ti, Oxygen, Mn, Si contains were $(1.09 \%, 4.84 \%, 9.93 \%$ and $3.51 \%)$ respectivey, for the welding specimen without $\mathrm{TiO}_{2}$ NPs. as shown in Figures 8 and 9.

Table 4 shows that the values of the $\mathrm{Ti}$, Oxygen, Mn, Si contains were $(1.27 \%, 11.86 \%, 8.56 \%$ and $3.06 \%)$ respectivey, for the welding specimen with $2 \% \mathrm{TiO}_{2} \mathrm{NPs}$ as shown in Figure 10. 


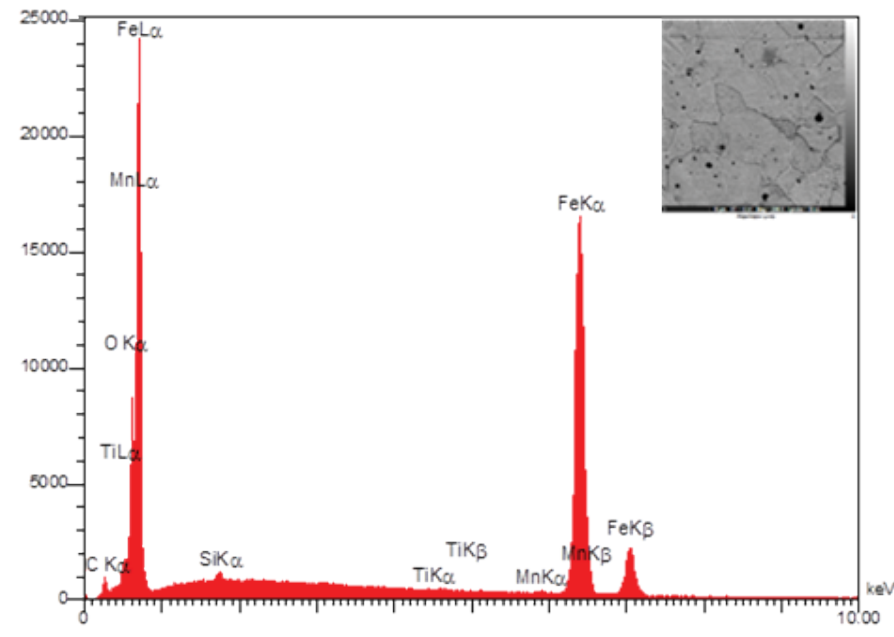

Figure 10: EDS analysis for the $\left(\mathrm{S}_{3}\right)$ welding specimen.

\section{CONCLUSION}

The effect of adding of $\mathrm{TiO}_{2} \mathrm{NPs}$ colloidal to weld joints welded by wire electrode E6013 in arc welding method had been investigated. The Impact toughness, and microstructure of samples had been studied.

- With the adding of $\mathrm{TiO}_{2}$ NPs colloidal to the welding joints, there was an increase in Impact toughness for welding area about $(42 \%)$ at adding ratio of $\mathrm{TiO}_{2}$ of $(1.5 \%)$

- Increasing the ratio of $\mathrm{TiO}_{2} \mathrm{NPs}$ in welding joints above $(1.5 \%)$ due to decrease in impact toughness. This is due to the increasing in the presenence ratio of oxygen.

- With the adding of $\mathrm{TiO}_{2}$ NPs colloidal to the welding joints, there was an increase in Ti contain and a decrease in $\mathrm{Mn}$, Si contain, led to an increase in quantity of acicular ferritethat lead to reduce the size of grains .

- The grain size of the welding area by wire electrode (E6013) with adding of $\mathrm{TiO}_{2}$ NPs was decreased.

- The SEM test, showed that increasing the content of titanium oxide led to the conversion of columnar zones from Widmanstätten ferrite and allotriomorphic ferrite to fine intragranular ferrite and refining the ferrite grain size of reheated zones.

\section{DECLARATIONS}

\section{- Avaibility of data and materials}

The results of data and materials presented clearly in manuscript but im not permission to present the data in manuscript as my co-authors refused that.

\section{- Competing interests}

Our manuscript have no competing interest (finintial and non-financial).

\section{- Funding}

We complete our manuscript without any funding, and spend on the manuscript from our money.

\section{- Author contributions}

The contribution for authors in manuscript were equaly disributed among three authors.

\section{ACKNOWLEDGEMENTS}

The authors would like to acknowledge the assistance offered by Nanotechnology and Advanced Materials Research Unit (NAMRU) and Laboratories of Mechanical Engineering, Department at Faculty of Engineering, University of Kufa/Iraq and the authors are thankful the Mechanical Workshop in Kufa Cement Plant/ Iraq.

\section{REFERENCES}

1. Zhang R, Gao L. Effect of peptization on phase transformation of $\mathrm{TiO}_{2}$ nanoparticles. Mater Res. 2001;36:1957-1965.

2. Ang JY, Mei S, Ferreira JM. Hydrothermal synthesis of nanosized titania powders: Influence of tetraalkyl ammonium hydroxides on particle characteristics. J Am Ceram Soc. 2001;84:1696-1702.

3. Wetzel B, Rosso P, Haupert F, Friedrich K. Epoxy nanocompositesFracture and toughening mechanisms. Eng Fract Mech. 2006;73:2375. 2398.

4. Nedjad SH, Farzaneh A. Formation of fine intragranular ferrite in cast plain carbon steel inoculated by titanium oxide nanopowder. Scr Mater. 2007;57:937-940.

5. Kiviö M, Holappa L, Iung T. Addition of dispersoid titanium oxide inclusions in steel and their influence on grain refinement. Metall Mater Trans B. 2010; 41:1194-1204.

6. St Laurent S, L'Espérance G. Effects of chemistry, density and size distribution of inclusions on the nucleation of acicular ferrite of C-Mn steel shielded-metal-arc-welding weldments. Mater Sci Eng A. 1992;149:203-216.

7. Zhang D, Terasaki H, Komizo YI. In situ observation of the formation of intragranular acicular ferrite at non-metallic inclusions in $\mathrm{C}-\mathrm{Mn}$ steel. Acta Mater. 2010;58:1369-1378.

8. Byun JS, Shim JH, Suh JY, Oh YJ, Cho YW, Shim JD, et al. Inoculated acicular ferrite microstructure and mechanical properties. Mater Sci Eng: A. 2001;319:326-331.

9. Byun JS, Shim JH, Cho YW. Influence of $\mathrm{Mn}$ on microstructural evolution in Ti-killed C-Mn steel. Scr Mater. 2003;48:449-454.

10. Gianetto JA, Smith NJ, McGrath JT, Bowker JT. Effect of composition and energy input on structure and properties of high-strength weld metals. New York, NY, USA. 1992;71:407-s.

11. Babu SS. The mechanism of acicular ferrite in weld deposits. Curr Opin Solid St M. 2004;8:267-278.

12. Gourgues AF, Flower HM, Lindley TC. Electron backscattering diffraction study of acicular ferrite, bainite, and martensite steel microstructures. J Mater Sci Technol. 2000;16:26-40.

13. Diaz-Fuentes M, Iza-Mendia A, Gutierrez I. Analysis of different acicular ferrite microstructures in low-carbon steels by electron backscattered diffraction. Study of their toughness behavior. Metallurgical and Materials Transactions A. 2003;34:2505-2516.

14. Fattahi M, Nabhani N, Vaezi MR, Rahimi E. Improvement of impact toughness of AWS E6010 weld metal by adding $\mathrm{TiO}_{2}$ nanoparticles to the electrode coating. Mat Sci Eng. A. 2011;528:8031-8039.

15. Pal TK, Maity UK. Effect of nano size $\mathrm{TiO}_{2}$ particles on mechanical properties of AWS E11018M type electrode. Mater Sci Appl. 2011;2:1285.

16. AWS board of directors. Specification for carbon steel electrodes for shielded metal arc welding. American National standards institute. 2004. 
17. American A, Standard N. Standard methods for mechanical testing of welds. 2007.

18. Diaz-Fuentes M, Iza-Mendia A, Gutierrez I. Analysis of different acicular ferrite microstructures in low-carbon steels by electron backscattered diffraction. Study of their toughness behavior. Metall Mater Trans A. 2003;34:2505-2516.

19. Ramkumar KR, Natarajan S. Investigations on microstructure and mechanical properties of $\mathrm{TiO}_{2}$ Nanoparticles addition in $\mathrm{Al} 3003$ alloy joints by gas tungsten arc welding. Mater Sci Eng: A. 2018;727:51-60.

20. Roy J, Rai RN, Saha SC. Effect of $\mathrm{TiO}_{2}$ enriched fluxes on the bead geometry, grain size and hardness in submerged arc welds. Int J Mater Prod Tec. 2018;56:313-325.

21. Grong O, Siewert TA, Martins GP, Olson DL. A model for the siliconmanganese deoxidation of steel weld metals. Metall Mater Trans A. 1986;17:1797-1807. 